\title{
A gênese das paisagens culturais do planalto sul brasileiro
}

\author{
SILVIA MOEHLECKE COPÉ ${ }^{I}$
}

\section{Introdução}

$\mathrm{N}$

OS ÚLTIMOS quinze anos, a arqueologia do planalto meridional brasileiro tem despertado renovado interesse, especialmente pelo substancial e consistente banco de dados produzidos por intensas e ininterruptas atividades de pesquisa desenvolvidas por diversas instituições acadêmicas, além de importantes aportes pontuais da arqueologia preventiva.

A pesquisa arqueológica no planalto inicia-se nos anos 1960 quando foi foco de estudos sistemáticos vinculados principalmente ao Programa Nacional de Pesquisas Arqueológicas (Pronapa, 1965-1970). Por meio dessas pesquisas foram definidas várias fases e três tradições arqueológicas denominadas Tradição Taquara (RS), Itararé (SC) e Casa de Pedra (PR), caracterizadas por ocupações pré-coloniais produtoras de um tipo de cerâmica pequena composta de potes e tigelas com variada decoração plástica e que estaria presente nos estados meridionais do Brasil desde o século II d.C. até o período da colonização europeia, quando passaram a ser identificados com as sociedades etnicamente ligadas ao tronco linguístico Jê, como os Kaingáng e Xókleng históricos. O nome da tradição Taquara provém de uma fase criada por Miller (1971) para o material encontrado no sítio litocerâmico superficial localizado no Morro da Formiga no município de Taquara (RS); entretanto, é utilizado para todos os tipos de sítios arqueológicos (estruturas subterrâneas e semissubterrâneas, montículos funerários, grutas, entre outros) e locais (o planalto, a encosta do planalto e o litoral) onde foram encontrados fragmentos cerâmicos semelhantes.

Nos anos 1980, a tese de Reis (1980) e a construção de uma usina hidrelétrica sobre o rio Pelotas demandaram um grande trabalho de prospecção e escavação no planalto, M. J. Reis em Santa Catarina, P. A. M. Ribeiro em Esmeralda (Ribeiro; Ribeiro, 1985 ) e A. A. Kern em Vacaria/Bom Jesus que, mesmo produzindo novos resultados e levantando questões pertinentes quanto à espacialidade dos sítios e reconstrução da vida social do grupo, levou Kern et al. (1989) a assinalarem a necessidade de aprofundar as pesquisas e formular novas perguntas.

Após esse trabalho, poucos avanços práticos e teóricos foram feitos até o final dos anos 1990 quando foram retomadas as atividades de campo pela nossa equipe do NuPArq/UFRGS e pelo IAP/Unisinos (Schmitz, 2002a), assim como realizados trabalhos acadêmicos (Reis, 2002; Silva, 2001) e trabalhos de sínteses (Noelli, 1999/2000). 
Essas investigações revelaram sofisticadas paisagens culturais construídas ao longo de milhares de anos por sucessivas ocupações humanas. Até o presente identificamos cinco momentos marcantes na construção social da paisagem cultural moderna do planalto sul brasileiro: 1. Os pioneiros grupos de caçadores e coletores que chegaram há mais de sete mil anos antes do presente; 2. Os caçadores, coletores e construtores de estruturas semissubterrâneas que se estabelecem no início da nossa era e se expandem entre os anos AD 800 e 1000; 3. Os caçadores, coletores e construtores de grandes aldeias superficiais e das estruturas funerárias e cerimoniais no período de $\mathrm{AD} 1.200$ até a conquista; 4. Os grupos Xokleng e Kaingang, falantes do tronco linguístico Jê e denominados Jê Meridionais, os grupos Guarani e o colonizador europeu; e 5. Os diversos grupos que constituem as comunidades atuais. A temporalidade da paisagem é o denominador comum deste ensaio, que versa principalmente sobre os dois momentos em que se destacam uma inusitada arquitetura doméstica, ritual e cerimonial.

As paisagens culturais constituem-se na interação entre o homem e a natureza ao longo da passagem do tempo. As paisagens culturais modernas exibem, por suas formas, estruturas e história de uso, aspectos que remetem à sua origem e desenvolvimento, contribuindo assim à biodiversidade atual, e representam um bem cultural que deve ser preservado enquanto herança regional e nacional. Portanto, o termo paisagem cultural é aqui usado porque cobre um amplo espectro, abarcando desde aspectos ecológicos, passando pela perspectiva histórica e a biodiversidade da paisagem construída, até o futuro manejo dessa paisagem herdada. As paisagens culturais formaram quem nós somos hoje (gaúchos, paulistas; enfim, os brasileiros), assim como são os lugares que habitamos e que estão sendo moldadas por nós. As paisagens culturais foram e são moldadas materialmente - por meio de todas as intervenções antrópicas no ambiente, e imaterialmente - pela projeção das ideias, fantasias e aspirações dos homens que as construíram (PAN, 2006).

O pensar paisagens culturais é uma decorrência da aplicação da abordagem da arqueologia da paisagem ao estudo dos sítios arqueológicos do planalto sul brasileiro e será trazido aqui mediante dois estudos de casos no nordeste do Rio Grande do Sul, mais especificamente nos municípios de Bom Jesus e Pinhal da Serra, distantes cem quilômetros entre si.

\section{A espacialidade da paisagem}

O planalto sul brasileiro é a porção meridional do planalto brasileiro que se estende pelos estados da Região Sul - Paraná, Santa Catarina e Rio Grande do Sul -, e apresenta, na sua constituição geológica, camadas de efusões vulcânicas basálticas sobrepostas ao arenito e às rochas cristalinas. Os terrenos são mais elevados próximos ao Atlântico, alcançando altitudes acima de mil metros, onde a Serra do Mar e a Serra Geral formam uma barreira montanhosa com relevos variados e pequenos planaltos de cobertura que perdem altitude em direção ao 
interior. Essa cadeia de escarpas elevadas apresenta, no Rio Grande do Sul, planaltos e vales cortados por rios das bacias do Uruguai e do Taquari/Antas que descem para as terras baixas. As altitudes de trezentos a mil metros são responsáveis por uma diminuição sensível das médias anuais de temperatura, oportunizando um clima temperado (Kern, 1991).

É sobre essa base geológica e geomorfológica que se organizam as variadas formações vegetais do planalto sul brasileiro. A Serra Geral está coberta pela floresta subtropical subcaducifólia densa e úmida, e sobre o planalto, a floresta subtropical subcaducifólia se complementa com pinheiros de araucárias (Araucaria angustifolia) e se alterna com campos cobertos de gramíneas, os chamados campos de cima da serra. As araucárias estão agrupadas sob forma de capões de mato ou se estendem sobre as vertentes dos vales de pequenos rios e arroios sob a forma de florestas galerias. Os campos encontram-se predominantemente nos interflúvios e constituem prolongamentos dos pampas da bacia do rio da Prata, assim como remanescentes do período frio e estépico da última glaciação, em regressão, portanto, desde os inícios da recolonização florestal (Alonso, 1997 apud Kern, 1991, p.46). A fauna é variada e, conforme as paisagens, encontram-se roedores, felinos, cão selvagem, quatis, lontras, tapir, veados, pecari, símios, tatus, tamanduá, preguiça, morcegos, rãs, aves, insetos, peixes e moluscos.

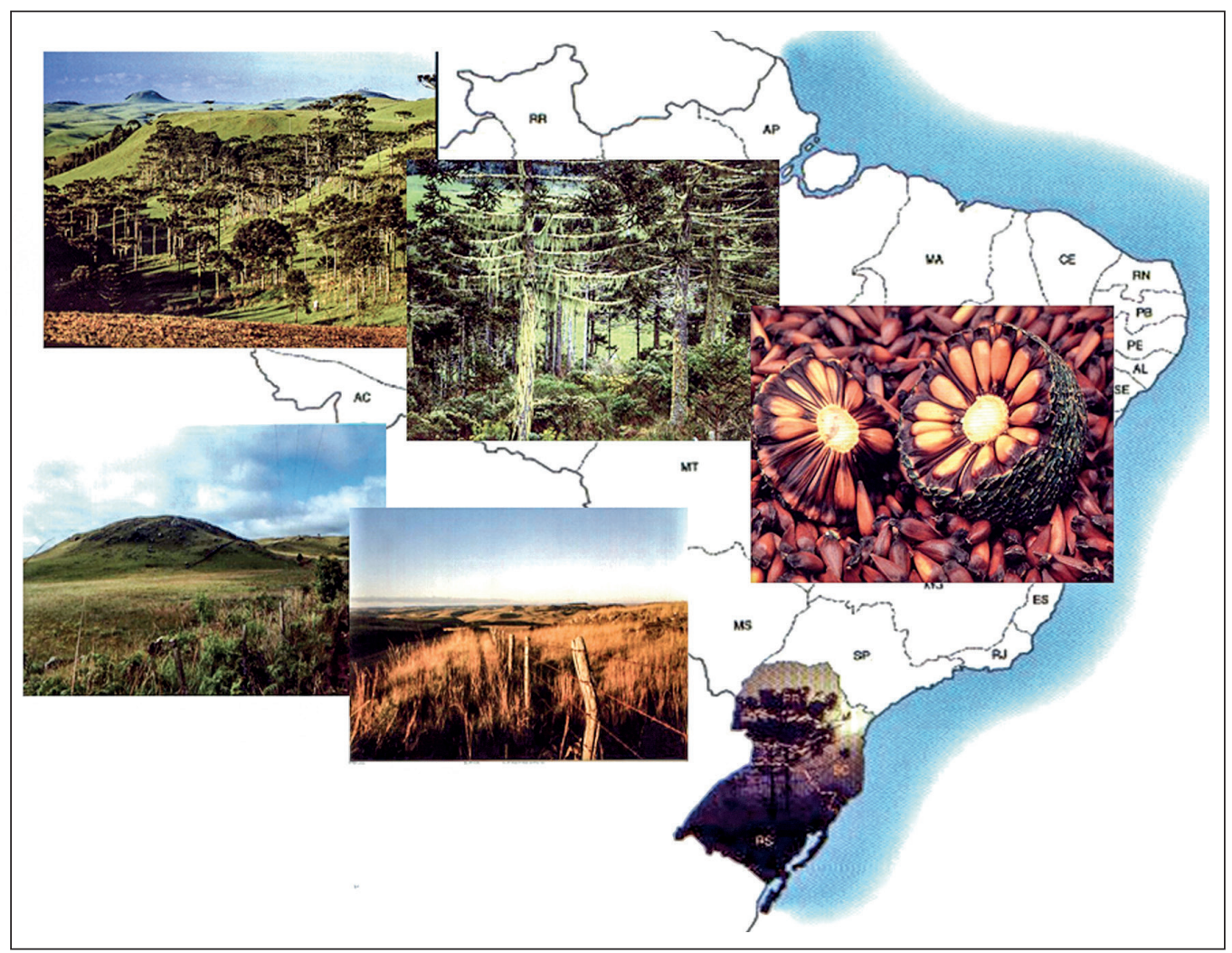

Figura 1 - A espacialidade da paisagem: a floresta subtropical subcaducifólia com pinheiros de araucárias alternada pelos Campos de Cima da Serra. 


\section{Revelando as paisagens culturais}

O estudo das terras altas do sul do Brasil mostra uma ampla variedade de tipos de sítios arqueológicos, como os conjuntos de estruturas escavadas no solo (popularmente denominadas de casas), sítios de estruturas circulares em alto relevo, sítios líticos e litocerâmicos superficiais, além de outras edificações como depósitos de terra, aterros, montículos funerários, galerias e muros de terra. A simples identificação de variados tipos de sítios não explica a forma como os seus construtores interagiram com o ambiente; no entanto, ela sempre foi interpretada como consequência de ocupações humanas diferenciadas ou, ainda, em períodos de tempo díspares. Nas áreas pesquisadas por nossa equipe, utilizando uma abordagem sistêmica e a premissa da contemporaneidade dos sítios, pressupomos que a variabilidade formal dos sítios provém de sua natureza e função (unidade residencial, comunitária, funerária, fonte de matéria-prima, depósito de entulho/lixo, área de produção e transformação dos alimentos e artefatos, entre outras) dentro do sistema de assentamento regional (Copé et al., 2002). Essa premissa só poderia ser comprovada ou descartada por meio da escavação sistemática de diferentes tipos de sítios arqueológicos, o que foi feito e apresentamos brevemente a seguir.

\section{As escavações de estruturas semissubterrâneas}

Entre 1999-2003, após prospectar uma área piloto de $15 \mathrm{~km}^{2}$ no município de Bom Jesus para registrar todos os sítios arqueológicos e escolher os mais importantes, escavamos o sítio RS-AN-03, composto de quatro estruturas cavadas no solo e um grande deposito de terra. Das quatro estruturas denominadas Casas A, B, C e D, escolhemos duas que possuíam tamanhos diferenciados Casa C com a abertura de 8 metros x 3 metros de profundidade, e Casa A de 18 de diâmetro e 6 metros de profundidade. A escavação dessas estruturas, do depósito de terra e do entorno do conjunto de estruturas foi realizada para definir principalmente as suas funções e delimitar a área do sitio (Copé, 2006d, 2012).

Os resultados da intervenção arqueológica na estrutura semissubterrânea pequena $(\mathrm{C})$ permitiram ter uma ideia clara dos elementos - paredes, bancadas, piso, fogueiras, esteios, vigas do telhado e telhado - que a compõem e o processo construtivo empregado. $\mathrm{O}$ processo construtivo compreendeu a abertura de um imenso buraco no solo e a constituição de paredes escavadas em rocha basáltica em decomposição, componente natural da elevação onde se localiza o conjunto do sítio. Obtivemos onze datas radiocarbônicas para as diferentes estruturas e podemos afirmar que a história do sítio RS-AN-03, principalmente da casa C, começa em torno do ano 1070 ap Cal AD 790 a 1050 (Beta - 178135), ou ainda bem mais cedo, ${ }^{1}$ e é reocupada por grupo com cerâmica Taquara e Guarani em 550 \pm 40 ap (Beta - 166584) AD 1310 a 1370 (Figura 2).

$\mathrm{Na}$ estrutura semissubterrânea grande (A) foram escavados somente 28 $\mathrm{m}^{2}$ devido às suas grandes dimensões, o que perfaz pouco mais de um terço de sua área total. A escavação permitiu evidenciar vários elementos como a parede 

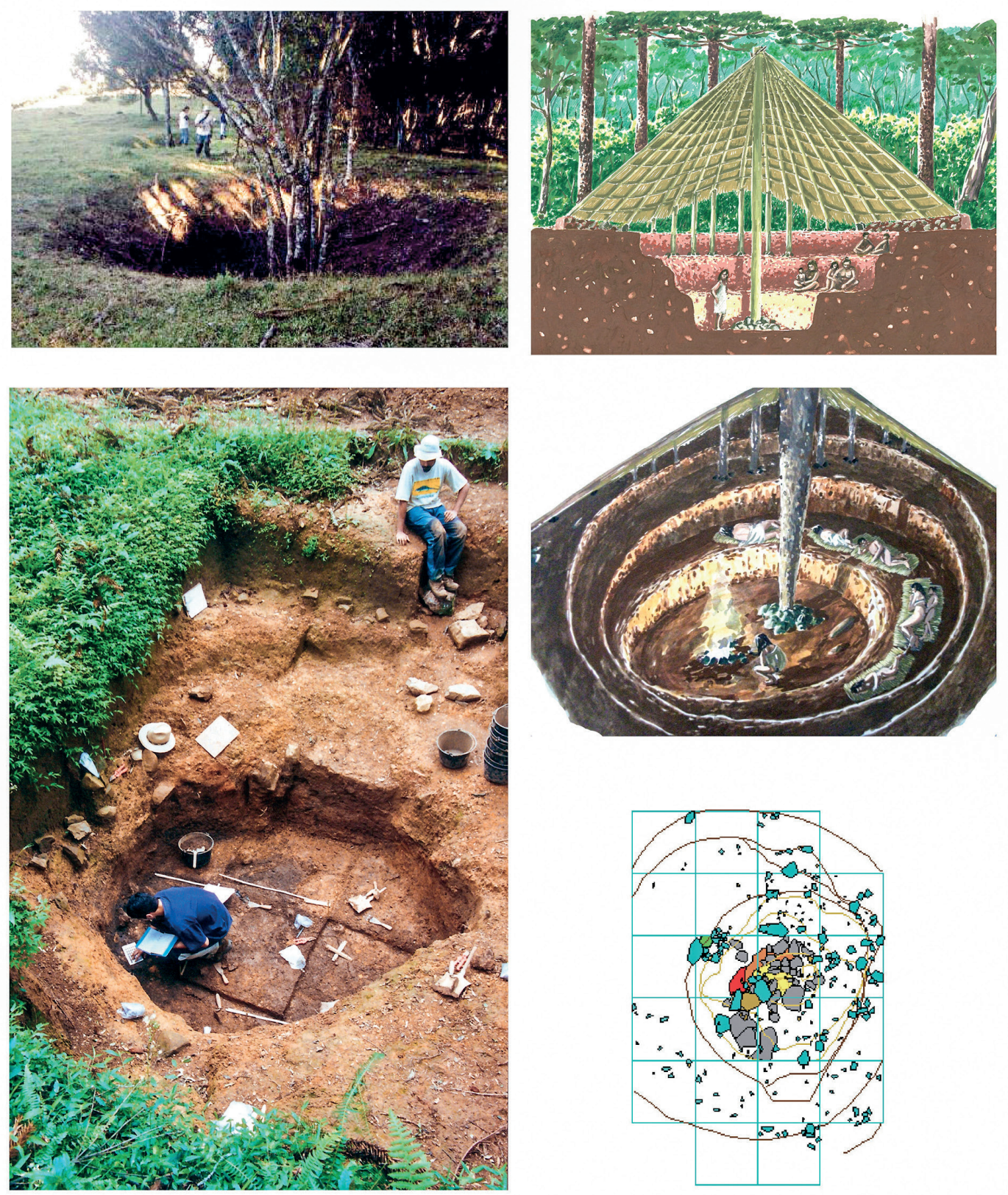

Figura 2 - A estrutura semissubterrrânea pequena (C) do sítio RS-AN-03, Bom Jesus (RS); a escavação e a planta baixa da camada mais antiga de ocupação; a interpretação dos dados por meio de ilustrações. Ilustração de Jorge Hermann.

Sul, o piso, fogueiras, buracos de postes (esteios) e o madeirame do vigamento do telhado. Na parte central leste da estrutura, as cinco fogueiras identificadas estavam estruturadas com blocos de rocha possuíam muito carvão no seu interior, e em duas foram encontrados fragmentos de uma vasilha cerâmica. A nossa hipótese é de que as fogueiras foram utilizadas concomitantemente, visto que em duas obtivemos as datas de 880 ap e 870 ap. Na fogueira 2 conseguimos 
comprovar a hipótese, que tínhamos levantado durante a escavação da estrutura $\mathrm{C}$, de que as fogueiras e o piso das estruturas passavam por periódicos rearranjos ou limpezas, pois essa fogueira encontrava-se quase que completamente coberta por uma camada de $3 \mathrm{~cm}$ de basalto decomposto. Também muito interessante é a distribuição espacial das fogueiras, formando um semicírculo ao redor do centro da estrutura o que nos permite supor um espaço ocupado por várias pessoas, talvez, além de uma unidade residencial, uma área comunitária (Figura 3).
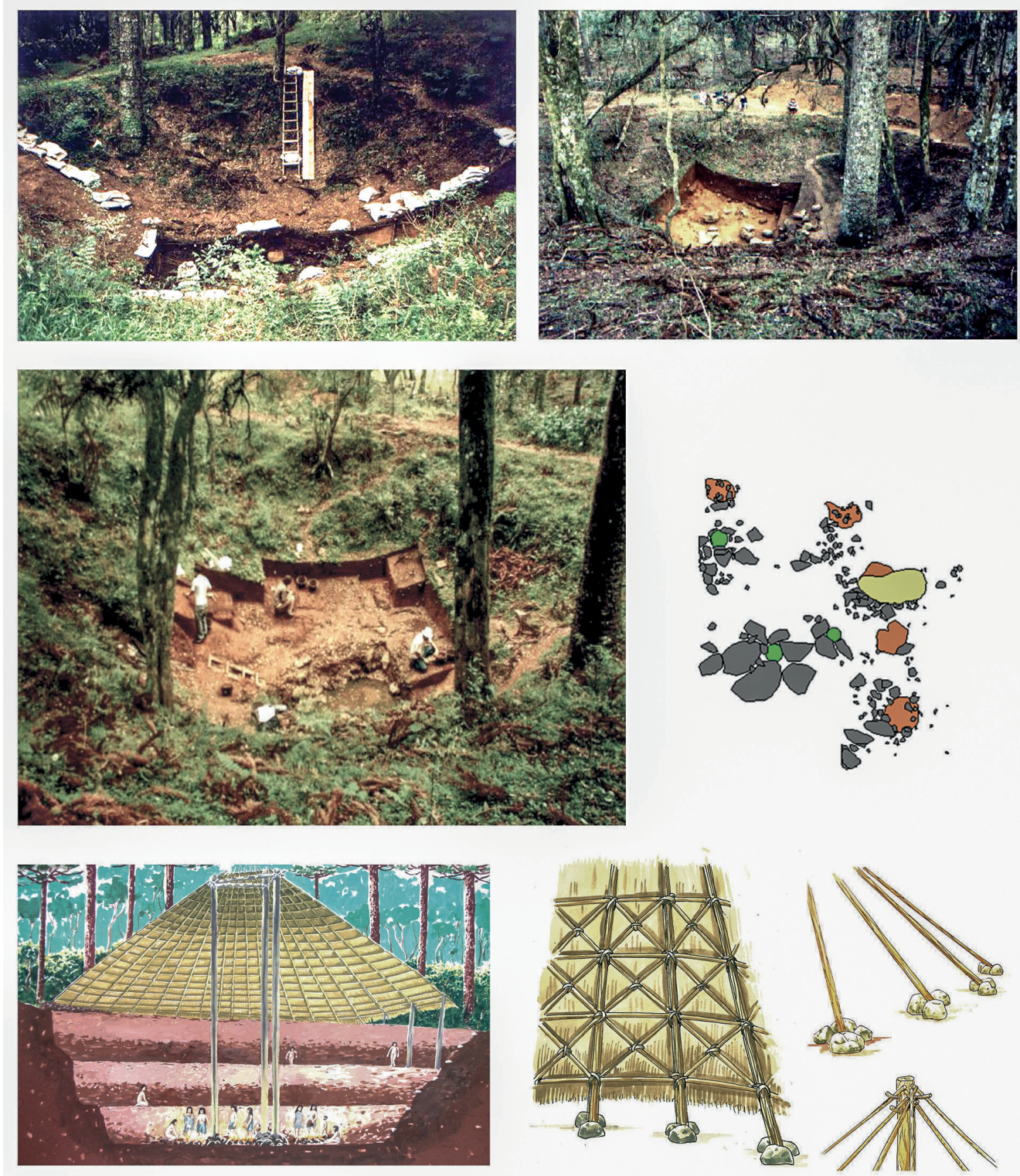

Figura 3 - A estrutura semissubterrrânea grande (A) do sítio RS-AN-03, Bom Jesus (RS); a escavação e a planta baixa da camada mais antiga de ocupação; a interpretação dos dados por meio de ilustração. Ilustração de Jorge Hermann. 
Quanto à função do sítio RS-AN-03, percebemos, portanto, que as estruturas semissubterrâneas foram utilizadas como unidades residenciais e à estrutura grande (A) poderia também agregar funções comunitárias ou pertencer a uma pessoa de status mais elevado. A cerâmica era de uso utilitário e o material lítico era de uso expediente e/ou de longa duração como as mãos de pilão. As atividades desenvolvidas foram de produção de artefatos para uso cotidiano nas tarefas de transformação e consumo de alimentos. A falta de grandes núcleos e evidências de lascamento inicial levantam a suposição de que essas atividades e de experimentação da matéria-prima se davam junto às fontes de afloramentos de basalto dispersos no planalto. Da mesma forma, a cerâmica deveria ser produzida fora das estruturas, talvez nas áreas externas, e a argila obtida nos barreiros junto aos tributários do rio das Antas.

A escavação realizada no imponente depósito de terra $(31$ x 13 x 3,48 m de altura) apresentou uma estratigrafia exatamente inversa das encontradas nas estruturas escavadas A e C, demonstrando o depósito tratar-se do acúmulo de terra proveniente da construção das estruturas escavadas. As escavações nas áreas externas as estruturas, além de seis fogueiras e de áreas de atividades de lascamento e processamento de alimentos, revelaram um sítio arqueológico com uma superfície cotidianamente utilizada de cerca de $8450 \mathrm{~m}^{2}$ (130 x 65 metros) (Figura 4).
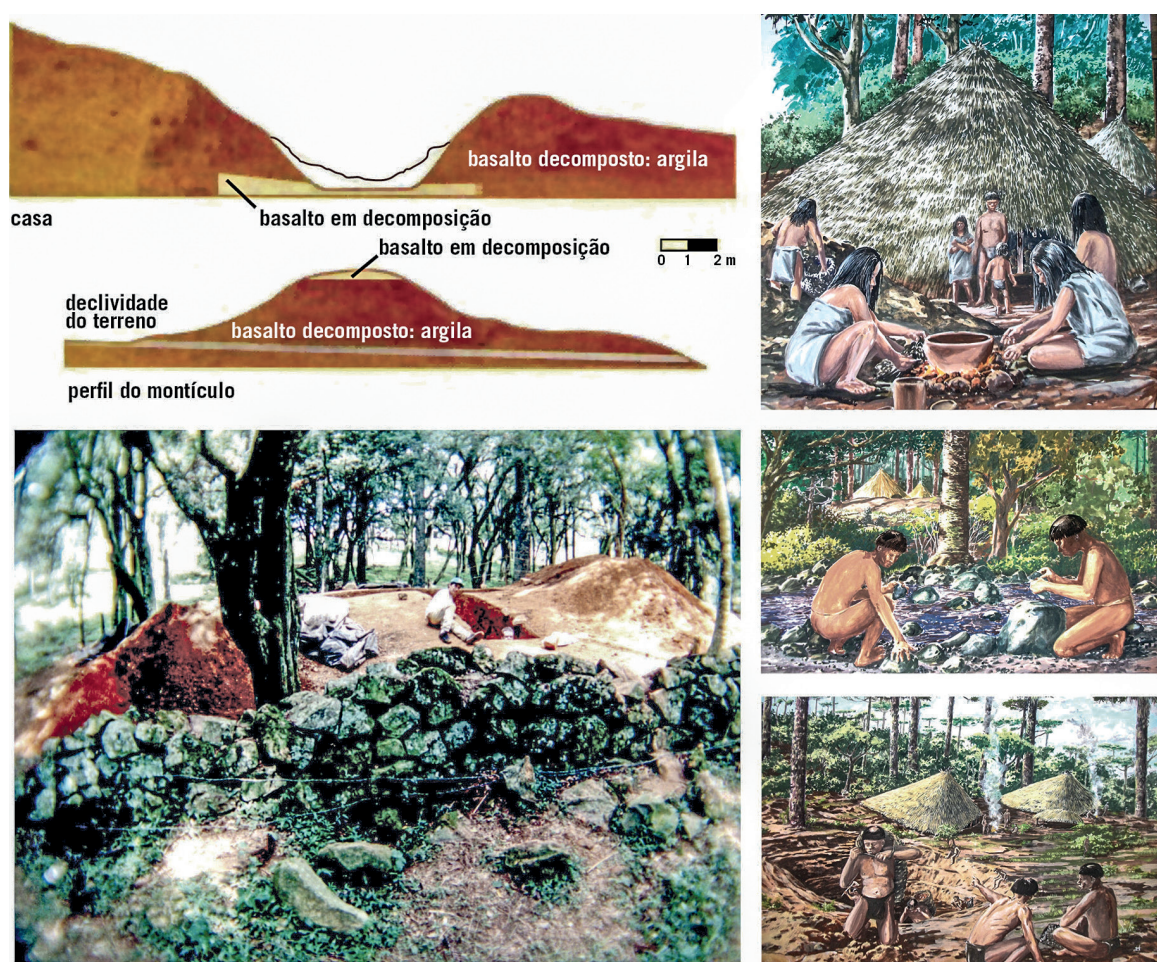

Figura 4 - O depósito de terra e o perfil estratigráfico (Schmitz, 2002b); ilustração do processo construtivo da estrutura semissubterrrânea grande; ilustrações das atividades cotidianas nas áreas externas. Ilustração de Jorge Hermann. 
$\mathrm{Na}$ tentativa de efetuar uma biografia do sítio, verificamos que, aparentemente, o grupo humano que aí se estabeleceu acampou no local do depósito de terra próximo ao córrego uma das muitas nascentes de arroios tributários do rio das Antas e começou a construção da estrutura semissubterrânea C, após, talvez construísse a B e D (silo?) e, conforme as datas disponíveis, duzentos anos depois, a estrutura $\mathrm{A}$. Como não finalizamos a escavação na estrutura $\mathrm{A}$, ela poderá fornecer datas mais antigas. Entretanto, o interessante é que as estruturas foram ocupadas ao mesmo tempo, portanto são contemporâneas. Algumas atividades como dormir, processar e consumir os alimentos poderiam ser realizadas tanto dentro da casa quanto fora, enquanto as de produzir os artefatos foram realizadas talvez exclusivamente na área externa (Figura 4). A escavação minuciosa permitiu analisar o processo de formação do sítio após o seu abandono (Figura 5).
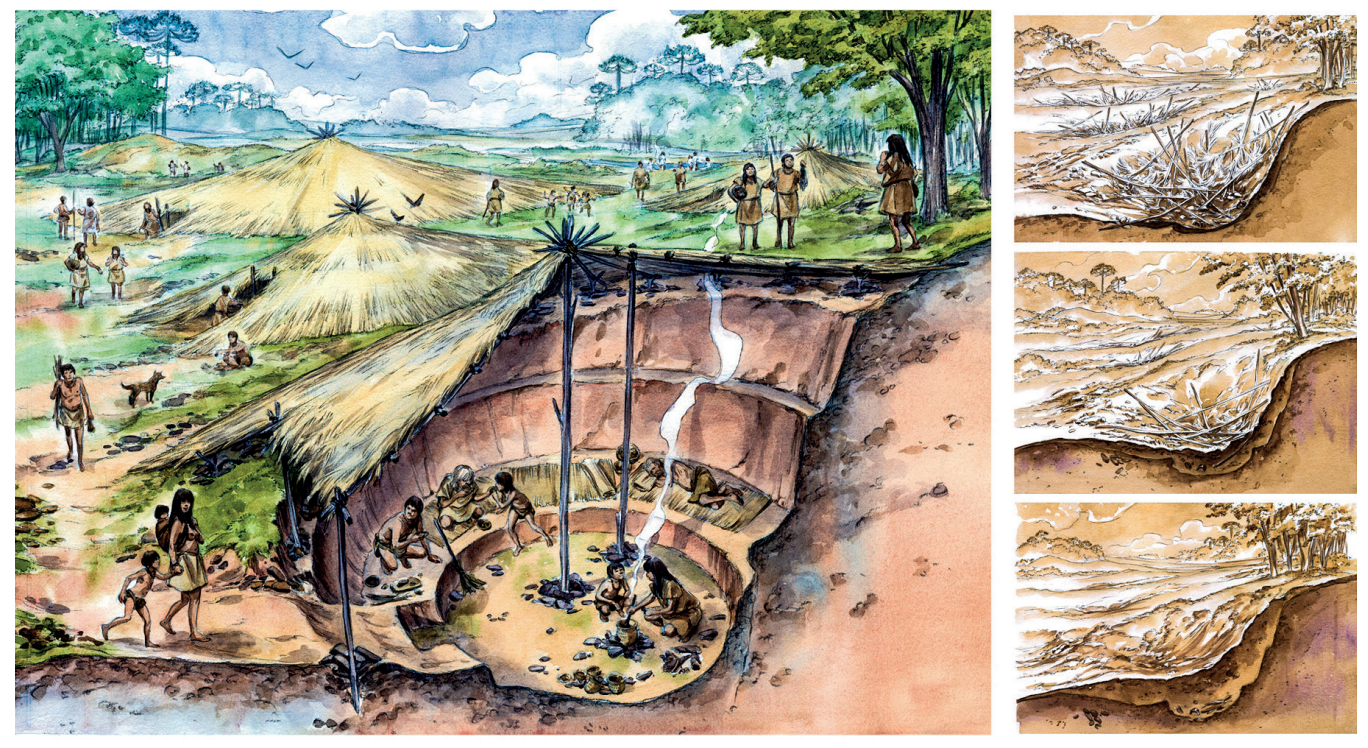

Figura 5 - Processo de formação do sítio RS-AN-03, Bom Jesus (RS), após o seu abandono. Ilustração de Ana Luiza Koehler.

\section{A arquitetura da paisagem pelos grandes construtores de estruturas semissubterrâneas: $A D 0$ a 1200, auge entre $A D 800$ e 1000}

Por meio de mapas de distribuição dos sítios, o padrão de assentamento verificado é que os conjuntos de estruturas semissubterrâneas ocupam as partes mais elevadas do planalto, localizadas nos morros que configuram as nascentes dos tributários do rio das Antas e do Pelotas, dominando os divisores de água e possuindo uma grande visibilidade sobre a região. A maioria dos sítios está na meia encosta, cujo declive abrupto foi utilizado como uma das paredes das estruturas. A implantação no relevo está relacionada aos processos construtivos, assim como por estratégia defensiva dos ventos gelados dos invernos rigorosos e dos inimigos. Na maioria dos casos, as estruturas escavadas dos sítios formam conjuntos e esses conjuntos também formam concentrações ou aglomerados, configurando 
aldeias. ${ }^{2} \mathrm{~A}$ arquitetura das estruturas semissubterrâneas é consequência de um sistema adaptativo expresso pela confiança em recursos alimentícios abundantes, ricos e previsíveis no período em que as estruturas dos sítios estão sendo ocupadas.

Ao longo dos últimos quinze anos e concomitantemente às nossas pesquisas arqueológicas no planalto, um grupo de ecólogos coordenado por Hermann Behling esteve estudando a dinâmica do fogo, da vegetação e do clima no planalto sul brasileiro durante o Quaternário antigo, por meio de amostras de carvão e pólen datados por alta resolução e pela análise multivariada. Os resultados mostram que o ambiente da mata de araucárias (onde os grupos humanos pretéritos tiravam a sua subsistência) e dos campos de cima da serra possui um forte componente dinâmico que é o próprio homem.

A partir de 1.500 ap, Behling $(2001,2002)$ supõe um aumento generalizado da umidade no sul do Brasil, com as mais curtas estações secas anuais desde o pré-Glacial (Behling, 1998). Esse aumento significativo da precipitação é o fator fundamental para a grande expansão da floresta de araucária sobre a vegetação de campo (Behling, 1995, p.147), o que ocorre com pequenas diferenças temporais desde o Paraná até o Rio Grande do Sul. Assim, essa expansão das araucárias e taxas acompanhantes parece ter início no planalto paranaense em $1.500 \mathrm{bp}$ (Behling, 1997), alcançado as terras altas de Santa Catarina por volta de 1.000 bp (Behling, 1995) e atingindo o atual Planalto das Araucárias gaúcho ao redor de 850 bp (Behling et al., 1999). No caso do Rio Grande do Sul, no município de São Francisco de Paula, há um aumento prévio de vegetação arbustiva e árvores em 1060 bp, e concomitância da expansão da floresta de pinheiro nativo com aumento da frequência de incêndios (ibidem), uma associação que pode ser favorável para a migração dessa floresta sobre os campos (Behling, 1997).

O surgimento tardio da mata de araucárias e sua expansão atribuída à ação de queimadas e manejo pelos grupos humanos ali residentes no passado permitem a hipótese de tratar-se de um ambiente domesticado pelo homem. Situação encontrada em outras partes já estudadas do Brasil, como na Amazônia (Balée, 1987; Neves, 2014), e do mundo, na Austrália e na África (Harris; Killman, 1989). Não deve ser por acaso que temos uma concentração de datações radiocarbônicas nesse período (Copé, 2006d, 2012; Bitencourt; Krauspenhar, 2006; Iriarte; Behling, 2007).

A expansão das florestas, em geral sobre os campos, traz um acréscimo na biomassa alimentar, o aumento da floresta de araucárias leva ao aumento de um alimento fundamental no planalto que é o pinhão que, na época de maturação (várias vezes ao ano), atrai toda sorte de animais, permitindo uma grande concentração de pessoas constituindo grandes aldeias de caráter permanente. $\mathrm{O}$ processo de ocupação ocorreu de maneira que, primeiro as parcelas desse grupo ocuparam as áreas mais baixas e ricas em florestas e, à medida que a floresta de araucárias se expande, vão domesticando o espaço, construindo-o socialmente, resultando em uma verdadeira arquitetura da paisagem. 

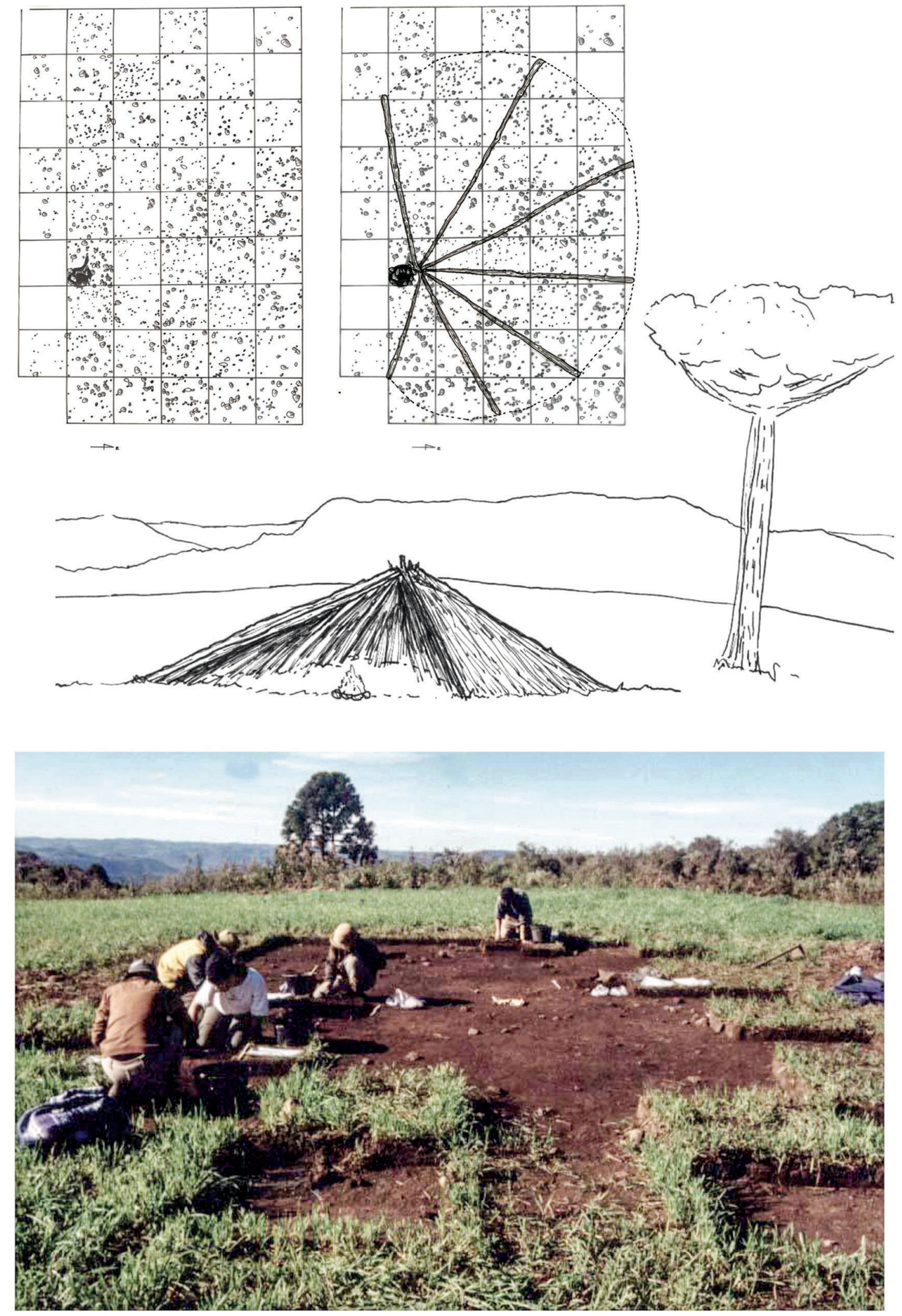

Figura 6 - Sítio litocerâmico superficial RS-PE-12, planta baixa e hipotética reconstrução. 
No período da primeira e mais antiga ocupação das estruturas semissubterrâneas, as práticas agrícolas não podem ser comprovadas. As evidências de plantas domesticadas, como o milho, foram encontradas em contexto funerário como oferenda (assim como a cerâmica na gruta do Matemático) e possivelmente foi introduzido mediante intercâmbio com os grupos agricultores Guarani em período bem posterior. Não foram encontradas evidências junto às unidades residenciais, assim como não foram encontrados os campos de cultivo, e os solos onde se encontram os sítios não são propícios à agricultura (ainda na atualidade a economia municipal é predominantemente voltada para a pecuária e a exploração da madeira). A análise de fitólitos dos resíduos encontrados em fragmentos de cerâmica da Casa C e A do sítio aqui analisado revelou o processamento exclusivo de plantas selvagens. Os artefatos, como mãos de pilão e cerâmica, poderiam estar associados às atividades de processamento da farinha do pinhão e não de produtos agrícolas.

\section{As grandes aldeias e a arquitetura funerária e cerimonial} em Pinbal da Serva (RS): AD 1200 ao periodo histórico

Ao longo de onze anos (2001 a 2011), as equipes do Núcleo de Pesquisa Arqueológica realizaram escavações em diversos tipos de sítios do município de Pinhal da Serra. Entre eles, o sítio arqueológico RS-PS-12 que se compõe de uma mancha de $1.780 \mathrm{~m}^{2}$, mais ou menos circular, de terra preta (a cor escura se deve a grande quantidade de material orgânico produzido pela ocupação humana passada), com material lítico e cerâmico na superfície. Apesar das evidências da passagem do arado, no lado leste da mancha, identificamos uma estrutura de fogueira formada de lascas e blocos de rocha dispostos em círculo e uma concentração de artefatos grandes em semicírculo ao seu redor. A data obtida para a fogueira é de $\mathrm{AD}$ 1460. A posição da fogueira e a distribuição dos artefatos permitem elaborar um modelo hipotético da estrutura: as atividades domésticas desenvolver-se-iam ao redor da fogueira e os detritos dessas atividades iriam acumulando-se junto às paredes da estrutura, formadas por madeirames dispostos radialmente que compunham o telhado revestido de palha (Copé et al., 2002) (Figura 6).

Apesar de esse tipo de sítio não ser alvo de investigações sistemáticas e somente registrada a sua existência na literatura arqueológica, essas concentrações de artefatos líticos e cerâmicos, associados à tradição Taquara, sempre foram interpretadas como aldeias compostas por pequenas choças de palha (Schmitz; Becker, 1991). Pela datação obtida e pelas suas características, interpretamos como sendo os sítios de habitação dos construtores das estruturas anelares com ou sem montículo central (Saldanha, 2005; Copé, 2007).

\section{A arquitetura funerária: os cemitérios}

Os sítios com estruturas em relevo são formados de muros de terra com alturas aproximadas de $0,5 \mathrm{~m}$, as estruturas são circulares ou losangulares ou, ainda, podem formar figuras mais complexa com tamanhos variados em cujo 
centro se encontra um ou mais montículos de terra. Esses sítios são compostos, na maioria dos casos, com duas estruturas de diferentes tamanhos. A primeira preocupação dos trabalhos nesse tipo de sítios foi a identificação da função, e para elucidar essa questão, realizamos a escavação no sítio RS-PE-21 e no RS-PE-29.

O sítio denominado RS-PS-21 consiste em dois aterros circulares de 15 e $20 \mathrm{~m}$ de diâmetro, ambos cercando montículos, e uma área de concentração de artefatos líticos e cerâmicos em superfície, com cerca de $1.400 \mathrm{~m}^{2}$. Foi aberta uma trincheira cortando parte do aterro da estrutura maior, bem como seu montículo central. Neste, aos $45 \mathrm{~cm}$ de profundidade, foi localizada uma microestrutura de fogueira com ossos calcinados, cercada por terra queimada (Copé et al., 2002). Esse achado confirmou a função funerária dos montículos, e desde então sítios semelhantes foram identificados e escavados no vale do rio Pelotas e do rio Canoas em Santa Catarina, quase sempre encontrando sepultamentos nos montículos (Herberts; Müller, 2007; De Masi 2006, 2009).
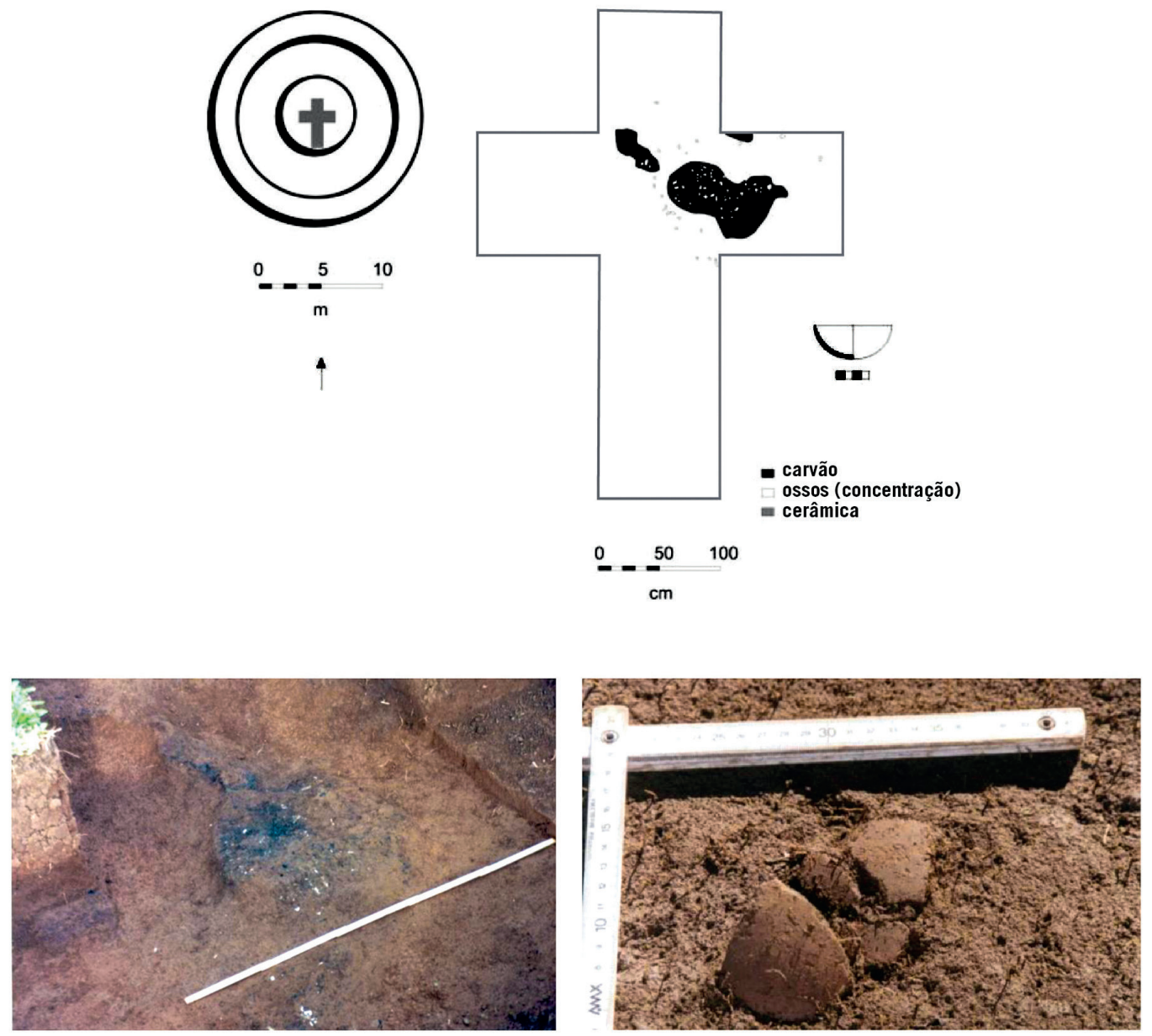

Figura 7 - Microestrutura de fogueira com ossos calcinados e fragmentos de cerâmica associados do sítio RS-PE-21. 
A coleta sistemática em 55 quadras de $5 \mathrm{~m}$ x $5 \mathrm{~m}$ revelou fragmentos cerâmicos em estágio avançado de desagregação (evidenciando uma queima de má qualidade), muitas bolotas de argila queimadas e roletes (demonstrando que houve a produção de cerâmica no local), além de instrumentos líticos. Apesar de os vestígios cerâmicos e líticos superficiais serem abundantes, a inexistência de uma camada arqueológica ou manchas pretas sugere que não havia estruturas residenciais nesse local, ou seja, as atividades ali evidenciadas pelos vestígios arqueológicos estão ligadas às estruturas funerárias circulares, distantes vinte metros. Essa área de deposição parece ter sido usada para o consumo e a transformação de alimentos (local de feasting?), bem como a produção de cerâmica (pela presença de bolotas de argila queimada), atividades que já foram evidenciadas em outro contexto funerário ligado a esses grupos (Saldanha, 2001, 2005).

Cerca de $400 \mathrm{~m}$ a noroeste, encontra-se a Estrutura 3 do sítio RS-PE-29, composta de dois círculos (denominados A e B) de $20 \mathrm{~m}$ de diâmetro, cada um cercando um montículo. Em 2008, escavamos o montículo central da Estrutura $3^{\mathrm{a}}$ e, aos $25 \mathrm{~cm}$ de profundidade, localizamos duas microestruturas, a primeira delas constituída por uma mancha acinzentada, pequenos nódulos alaranjados, carvões e ossos calcinados. Após completamente escavada a microestrutura, retirados todos os ossos e carvões, foi possível observar que essa se assentava sobre um aprofundamento da camada, formando uma cova. A segunda microestrutura, localizada ao lado da primeira, consistia em diversos carvões de grandes dimensões e ossos calcinados cercados por terra queimada. A disposição e alinhamento dos carvões, alguns paralelos, outros perpendiculares, permitem visualizar a forma da pira funerária. As datações feitas a partir do carvão associado aos ossos revelaram que essas duas microestruturas não são contemporâneas, sendo a primeira datada de $490 \pm 40 \mathrm{bp}$, cal AD 1410 a 1440 (Beta-242869), e a segunda de $340 \pm 40 \mathrm{bp}$, cal AD 1480 a 1630 (Beta-242860). Esta última parece ser contemporânea ao sepultamento no sítio RS-PE-2l cuja datação se situou em $350 \pm 40 \mathrm{bp}$, cal AD 1480 a 1630 (Beta-242868). Ocorrem, portanto, tanto sepultamentos primários quanto secundários. Esses dois padrões foram também observados em sítios escavados em Santa Catarina, onde, assim como em Pinhal da Serra, ambos os padrões eram por vezes encontrados associados sob o mesmo montículo (Herberts; Müller, 2007; De Masi, 2006, 2009; Souza; Copé, 2010)

Muitos dos montículos funerários estão nas proximidades de algum conjunto de casas subterrâneas e de grandes sítios litocerâmicos e podem corresponder a cemitérios locais dessas comunidades. Celebrações funerárias elaboradas reforçam os laços comunitários por meio da construção de uma memória coletiva representada pelos ancestrais falecidos. Esse é um aspecto que transparece especialmente nos sepultamentos secundários e múltiplos, como encontramos no planalto meridional. Cremação, limpeza, seleção dos ossos e seu transporte para o local definitivo de sepultamento, por vezes junto com outros indivíduos, além da construção do montículo e do aterro, revelam grande esforço coletivo (Saldanha, 2005; Souza; Copé, 2010). 

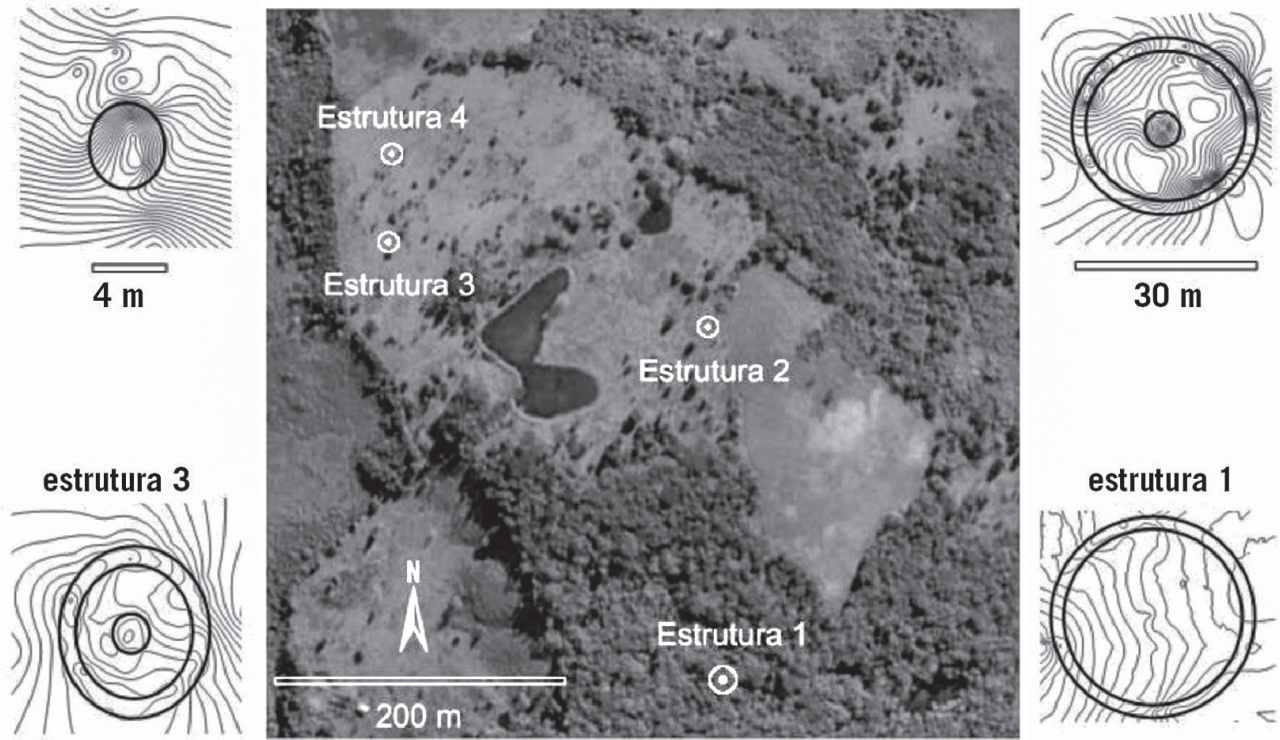

estrutura 3
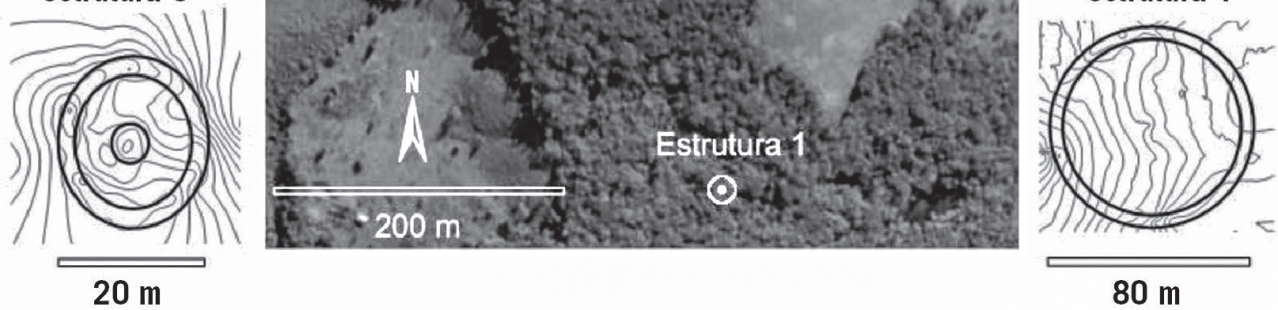

$80 \mathrm{~m}$
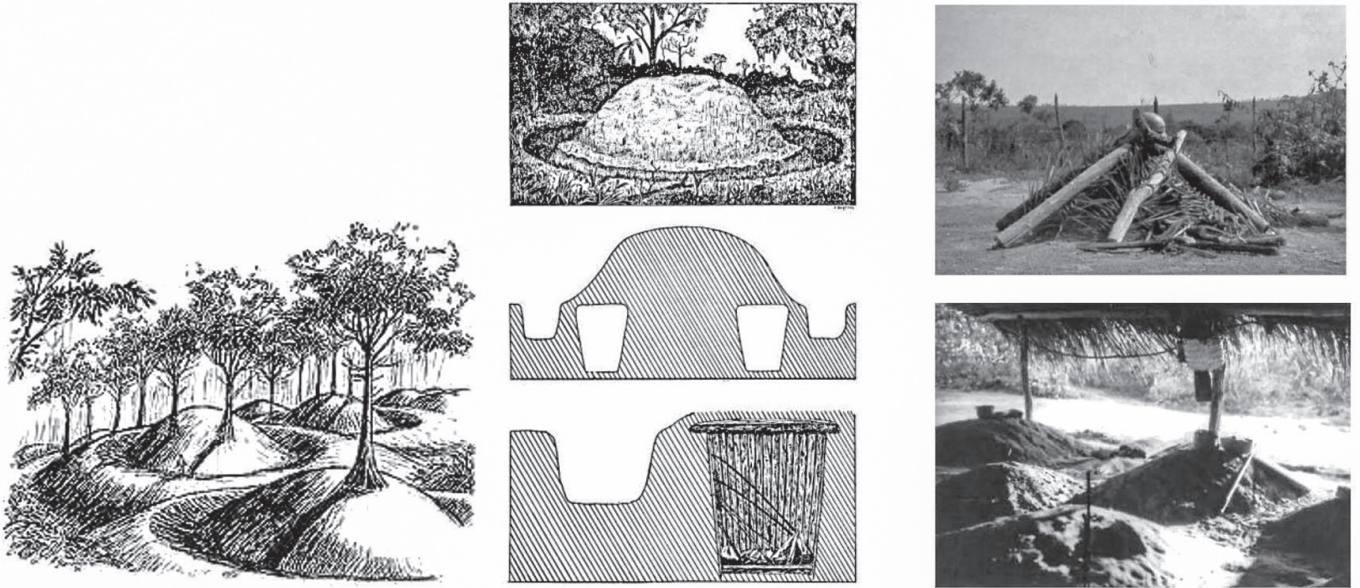

Figura 8 - As estruturas anelares do sítio RS-PE-29; desenho de sepultamento de Kaingang do século XIX, de Xokleng por Mabilde (1983) e enterramento moderno.

\section{A arquitetura cerimonial}

Todas as estruturas do sítio RS-PE-29 foram construídas no topo alongado de um morro, em uma altitude de $900 \mathrm{~m}$, com ampla vista dos arredores. A Estrutura 1 possui as maiores dimensões da região: trata-se de um aterro circular com $80 \mathrm{~m}$ de diâmetro, porém sem montículo em seu centro. A fim de resolver a questão da procedência da terra usada na construção do anel e o processo construtivo, abrimos duas trincheiras, uma cortando o aterro e outra na área interna cercada por ele, além de poços-teste nas áreas externas, fora da estrutura. A comparação da estratigrafia das diferentes áreas é um primeiro indício de que 

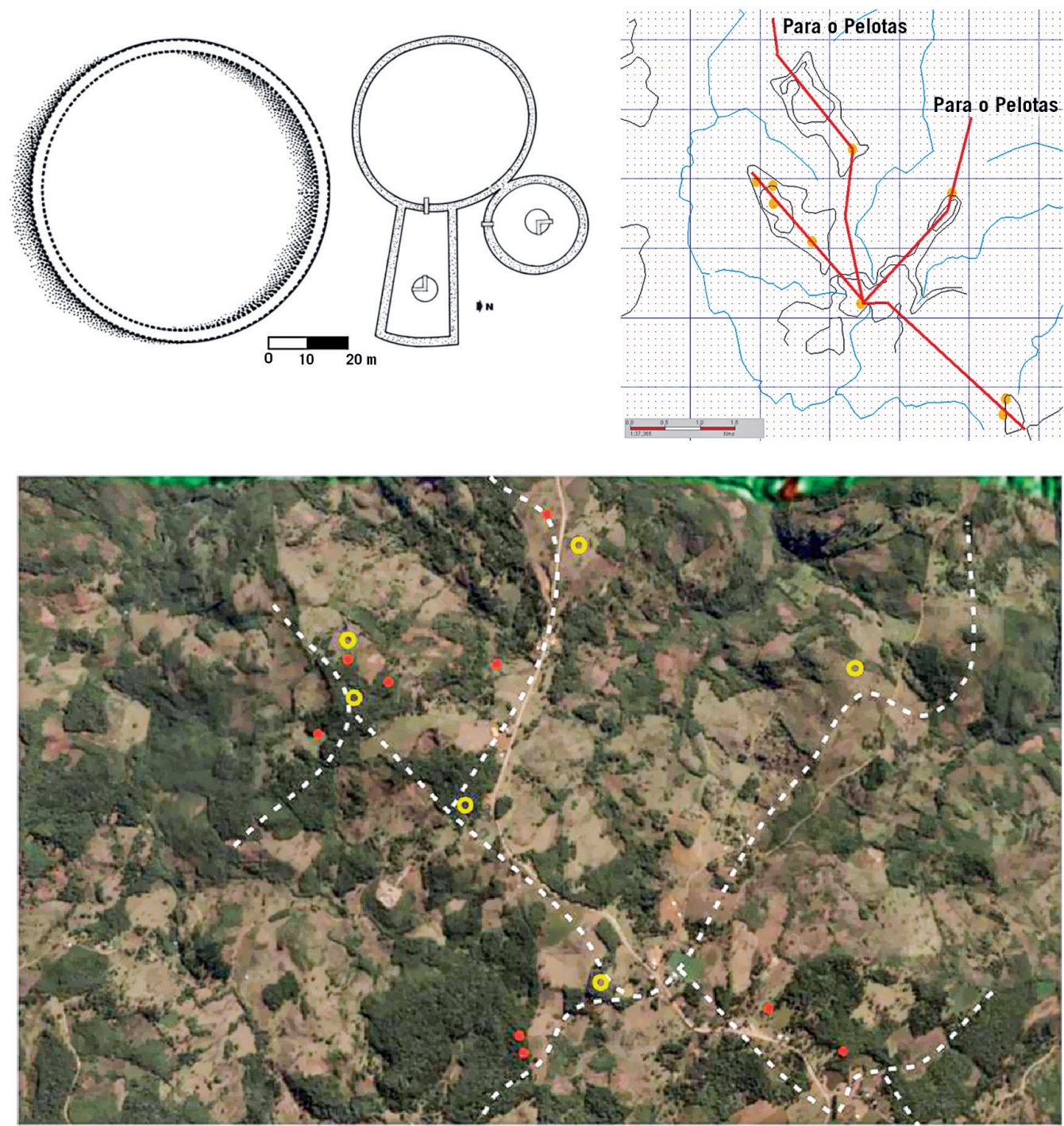

estrutura anelar

- casas subterrâneas

Figura 9 - Planta da estrutura 1 do sítio RS-PE-29 e do RS-PE-31; Imagem de satélite do Google Earth evidenciando as estruturas anelares (em amarelo) nos pontos nodais da paisagem; mapa mostrando os percursos mais fáceis e a ampla visibilidade a partir da estrutura anelar cerimonial do sítio RS-PE-29.

o aterro anelar foi construído com terra vinda de outro local, embora análises de solo ainda estejam para ser realizadas, de modo a fundamentar essa hipótese (Souza; Copé, 2010).

Esse tipo de sítio foi inicialmente estudado na província argentina de $\mathrm{Mi}$ siones, cidade de Eldorado, onde, no topo de um morro com boa vista dos arredores, um aterro circular de $180 \mathrm{~m}$ de diâmetro cercando um montículo em associação com cerâmica Taquara (chamada então de Eldoradense) e unido a 
outros quatro aterros circulares foi descrito pelo arqueólogo Oswald Menghin, que o interpretou como remanescente de uma antiga paliçada cercando um túmulo, representado pelo montículo, à semelhança das atuais aldeias circulares Jê (Ribeiro; Ribeiro, 1985, p.86). Posteriormente, sítios similares foram identificados no planalto leste de Santa Catarina, nos arredores de Urubici, pelo arqueólogo João Alfredo Rohr (1971). Dos sítios visitados por Rohr, os aterros menores, de 15 e $20 \mathrm{~m}$ de diâmetro, cercavam montículos, ao passo que os de maiores dimensões, entre 30 e $70 \mathrm{~m}$ de diâmetro, não apresentavam montículo em seu centro. Apesar da denominação popular de "danceiros" ou "terreiros de dança dos bugres", Rohr conclui a partir de suas escavações que tais sítios seriam remanescentes de antigas aldeias fortificadas, uma interpretação similar à de Menghin (Souza; Copé, 2010).

Em relação aos "danceiros", não há equivalentes etnográficos da construção dos monumentais aterros anelares. Contudo, De Masi $(2006,2009)$ faz uso de analogia com os locais onde os Xokleng realizavam o rito de iniciação que envolvia a perfuração dos lábios dos meninos, pois identificou, em um dos "danceiros" escavados (sítio SC-AG-12), um grande número de estruturas de combustão na praça central, além de estatuetas de argila e um tembetá de quartzo, confirmando o caráter ritual do sítio e sua possível conexão com as práticas Xokleng descritas na etnografia (Souza; Copé, 2010).

Entre 2009 e 2011, em projeto financiado pela Wenner-Green Foundation e parceria entre o NuPArq/UFRGS, a University of Exeter (Inglaterra), o Arkansas Archaeological Survey (Estados Unidos) e a University of South Carolina (Estados Unidos), realizaram-se prospecções geofísicas, levantamentos topográficos com GPS diferencial e escavações que ampliaram o entendimento da organização da paisagem Proto-Jê do Sul na região de Pinhal da Serra. O mapeamento cuidadoso das estruturas de aterros anelares com equipamentos de alta tecnologia demonstrou em detalhes a sucessiva utilização do espaço no topo dos morros para efetuar os sepultamentos, os espaços abertos que poderiam ser a entrada das estruturas anelares com montículos, os caminhos de circulação entre estruturas e os diversos momentos de construção de uma estrutura anelar complexa (Iriarte et al., 2013).

Do ponto de vista geomorfológico, os diferentes artefatos arquiteturais estão em posições extremamente semelhantes sobre os divisores de águas. No entanto, demonstraram uma diferença significativa na escolha dos locais para as estruturas semissubterrâneas e em alto relevo. As estruturas semissubterrâneas estão inseridas em áreas que se poderiam denominar distritos na paisagem, junto aos locais de caminhos mais fáceis. Do ponto de vista da visualização, esses locais são os mais avantajados, com amplo domínio da paisagem no entorno. Por outro lado, as estruturas em alto relevo estão inseridas em pontos nodais da paisagem, pontos para onde os caminhos convergem e divergem. Todos esses elementos, obtidos a partir de análises em SIG, apontam para conclusão que os 
espaços onde essas estruturas foram inseridas eram percebidos de maneira diferenciada pelos seus construtores (Saldanha, 2005).

\section{A temporalidade da paisagem}

A descrição sumária dos resultados de algumas intervenções (das inúmeras realizadas entre 1999-2011) em diferentes sítios arqueológicos foi aqui trazida para ressaltar a diversidade do registro arqueológico no espaço e no tempo. Simultaneamente à busca de uma história de longa duração, as rupturas e descontinuidades devem ser consideradas na construção de narrativas sobre histórias regionais, como a construção da paisagem cultural no planalto sul brasileiro. Por isso utilizamos o termo no plural, pois na gênese da paisagem moderna do planalto identificamos outros momentos importantes de construção que constituem um verdadeiro palimpsesto, "onde, mediante acumulações e substituições, a ação das diferentes gerações se superpõe" (Santos, 1996).

Os modelos projetados pelos linguistas e etnógrafos nos ajudam a levantar hipóteses e testá-las, mas não deveriam condicionar a leitura do registro arqueológico. Na produção bibliográfica sobre a arqueologia do planalto há uma forte tendência de relacionar as tradições ceramistas Taquara, Itararé e Casa de Pedra, as casas semissubterrâneas e as estruturas anelares aos grupos Jê do Sul (Noelli, 1999/2000) ou aos Proto-Jê (Silva, 2001); entretanto, como ressaltou Schmitz (2006, p.23) e reiteramos, é difícil provar arqueologicamente que as casas subterrâneas foram construídas pelos grupos produtores da Tradição Taquara e/ou pelos grupos etnográficos Jê. Não há homogeneidade no registro arqueológico, portanto é um sofisma acreditarmos que a cerâmica da Tradição Taquara, atribuída aos grupos Jê e encontrada também em casas subterrâneas, leva a associação automática entre essas estruturas e esses grupos.

Outra associação automática e aqui questionada é que os povos que ocupavam as casas semissubterrâneas eram agricultores. As evidências de agricultura, grãos de milho encontrado em contexto funerário, não estão datadas e quando associadas às casas semissubterrâneas são fruto da reocupação dessas no terceiro período de construção social da paisagem e/ou ocupações mais recentes como em Ubirici em SC (Corteletti, 2012).

Como vimos na Introdução deste artigo, até o momento presente e segundo os resultados das pesquisas arqueológicas efetuadas no nordeste do Rio Grande do Sul, conseguimos identificar cinco momentos na construção social da paisagem do planalto sul brasileiro, sendo o segundo momento o dos grandes construtores de estruturas semissubterrâneas que chegam ao sudeste de Santa Catarina e nordeste do Rio Grande do Sul em torno do início de nossa era, atingindo um período de expansão entre AD 800 e 1000. Em torno de 1200, abandonam a área ou modificam a maneira de interação com a paisagem construindo grandes aldeias, reocupando algumas estruturas semissubterrâneas e desenvolvendo uma arquitetura monumental funerária e cerimonial após AD 1200 ao período histórico. 
Consideramos que as paisagens culturais do planalto sul brasileiro, especialmente as estudadas no vale do rio Pelotas e, mais especificamente, nos municípios de Bom Jesus e Pinhal da Serra (RS) constituem um patrimônio paisagístico. E o olhar para as paisagens culturais do planalto sul brasileiro como patrimônio paisagístico permite percebê-las como um palimpsesto resultante de uma longa história de interações entre elementos naturais e culturais evidenciadas pelas marcas deixadas no espaço/território (landmarks), marcas essas caracterizadas por elementos estruturais/arquiteturais que oferecem referências dos lugares domésticos dos grandes construtores em terra, dos lugares dos rituais funerários e cerimonial dos Proto-Jê e dos grupos Jês meridionais, dos caminhos das tropas e do tropeirismo. Isso permite identificar valores patrimoniais nas paisagens do planalto, reconhecendo-as como bens culturais.

No planalto sul brasileiro, o vale do rio Pelotas, integrante da bacia do rio Uruguai, é um importante corredor ecológico coberto de mata atlântica e de floresta ombrófila com araucárias entremeadas de campos, apresentando uma grande biodiversidade natural e cultural com uma longa história, o que o torna um forte candidato a obter a chancela do Iphan como Paisagem Cultural Brasileira. $^{3}$

Para Milton Santos (1996), a paisagem existe por meio de suas formas, criadas em momentos históricos diferentes, porém coexistindo no momento atual, a paisagem é transtemporal, juntando objetos do passado e do presente, uma construção transversal.

Gostar-se-ia de mostrar neste ensaio que o patrimônio (considerado aqui como um bem cultural) e a paisagem (enquanto espaço físico natural e cultural) são temas transversais, ou seja, que tratam de processos vividos pela sociedade, debatidos em diferentes espaços sociais, que visam aprender sobre a realidade e a intervir nela para transformá-la (Gallo, 2010). E que as contribuições da arqueologia no estudo de paisagens contemporâneas estão na possibilidade de resgatar a gênese e o desenvolvimento da paisagem em análise; na ampla cobertura temporal e espacial, ou seja, nos estudos de longa duração; ${ }^{4}$ na multidisciplinaridade da arqueologia; $; 5$ na geração de uma herança cultural $;{ }^{6}$ no gerenciamento do patrimônio ${ }^{7}$ e na criação de vínculos da população atual com as que a procederam na construção das paisagens ocupadas. ${ }^{8}$

\section{Notas}

1 Uma amostra obtida ao nível 180-200 da camada 2 da quadrícula 113/117 forneceu uma data de $2180 \pm 40$ ap (Beta - 166587) ou Cal 380 a 160 a. C. Sempre desconsideramos a data por ser muito antiga para o planalto sul brasileiro; entretanto, achados recentes em Santa Catarina, por De Masi (2006) e pela equipe de P. I. Schmitz ( 2010), trazem datas tão antigas quanto a nossa.

2 A contabilização das estruturas escavadas no solo no planalto meridional atinge mais 2.200 depressões, que podem estar isoladas (geralmente são grandes) ou em conjuntos 
de mais cem (de tamanho médio a pequeno); entretanto, são mais frequentes os conjuntos de três a cinco estruturas. As estruturas semissubterrâneas encontram-se predominantemente em cotas altas, acima dos $800 \mathrm{~m}$ de altitude.

3 A chancela da Paisagem Cultural é o mais novo instrumento de preservação do patrimônio cultural brasileiro, lançado em 2009 pelo Iphan. Conforme a Portaria Iphan n.127/2009, que regulamenta essa chancela, "Paisagem Cultural Brasileira é uma porção peculiar do território nacional, representativa do processo de interação do homem com o meio natural, à qual a vida e a ciência humana imprimiram marcas ou atribuíram valores". Disponível em: <http://portal.iphan.gov.br/portal/baixaFcdAnexo. do? id=1756>.

4 A Arqueologia é a única disciplina com informações sobre as sociedades humanas desde as suas origens (desde o surgimento do gênero humano) e cobre todas as partes do globo ocupadas pelo homem.

5 Os achados arqueológicos somente são passiveis de ser interpretados quando contextualizados espaço-temporalmente; por exemplo, as informações sobre o contexto imediato exige conhecimentos de pedologia, sobre o entorno do sítio da ecologia etc.

$6 \mathrm{O}$ resgate arqueológico gera uma herança cultural.

7 Considerando que o arqueólogo quando escava destrói parcialmente o seu objeto de estudo, e que quando decide o quê, o como, e de que forma fará o registro dos dados está decidindo o que será preservado ou não, ele está gerenciando o patrimônio, o que abre dialogo com os demais gestores do patrimônio.

8 A intenção de recortar espaços simbólicos nas paisagens criando lugares excepcionais e de acesso exclusivo parece remontar a diversas sociedades e períodos distintos e não é um fenômeno exclusivamente moderno.

\section{Referências}

BALÉE, E. L. Cultural Forest of the Amazon. Garden, v.11, n.6, p.12-14, 1987.

BEHLING, H. Investigations into the Late Pleistocene and Holocene history of vegetation and climate in Santa Catarina. Vegetation History and Archaeobotany, v.4, p. $127-52,1995$.

Late Quaternary vegetation, climate and fire history of the Araucaria forest and campos region from Serra Campos Gerais, Paraná State (South Brazil). Review of Palaeobotany and Palynology, v.97, p.109-21, 1997.

. Late Quaternary vegetational and climatic changes in Brazil. Review of Palaeobotany and Palynology, v.99, p.143-56, 1998.

Vegetational and climate dynamics in southern Brazil during Late Quaternary times. In: VIII CONGRESSO DA ABEQUA. ABEQUA-Boletim de Resumos. Mariluz, Imbé, 2001.

. South and southeast Brazilian grasslands during Late Quaternary times: a synthesis. Palaeogeography, Palaeoclimatology, Palaeoecology, v.177, p.19-27, 2002.

BEHLING, H.; NEGRELLE, R. Tropical rain forest and climate dynamics fo the Atlantic Lowland, Southern Brazil, during Late Quaternary. Quaternary Research, v.56, 2001. 
BEHLING, H. et al. Holocene Environmental changes from São Francisco de Paula region in southern Brazil. In: VII CONGRESSO DA ABEQUA. Porto Seguro, 1999.

BEHLING, H. et al. Late Quaternary Araucaria fores, grassland (Campos), fire and climate dynamics, studied by highresolution pollen, charcoal and multivariate analysis of the Cambará do Sul core in southern Brazil. Palaeogeography, Palaeoclimatology, Palaeoecology, v.203, p.277-97, 2004.

BEHLING, H. et al. Late Quaternary grassland (Campos), gallery forest, fire and climate dynamics, studied by pollen, charcoal and multivariate analysis of the São Francisco de Assis core in western Rio Grande do Sul (Southern Brazil). Review of Palaeobotany and Palynology, v.133, p.235-48, 2005.

BITENCOURT, A. L. V.; KRAUSPENHAR, P. M. Possible prehistoric anthropogenic effect on Araucaria Angustifolia (Bert.) O. Kuntze expansion during the late Holocene. Revista Brasileira de Paleontologia, v.9, n.1, p.109-16, 2006.

BUENO, F. Campos de Cima da Serra e outras imagens da Serra. Agenda Calendário da Impresul. 2001

CABRAL, M. P. Projeto Pré-história do Planalto: estudo de paisagens arqueológicas em Bom Jesus e São José dos Ausentes, RS. Porto Alegre: NUPArq/UFRGS, 1999-2003.

CHAVES, R.; KOCH, Z. Região Sul: cores e sentimentos = South of Brazil: colors and feelings. São Paulo: Escrituras Editora, 2003.

COPÉ, S. M. Les grands constructeurs précoloniaux du plateau du sud duBrésil: étude de paysages archéologiques à Bom Jesus, Rio Grande do Sul, Brésil. 2006. Thèse (Doctorat) - Université Paris I, Panthéon, Sorbonne. Paris, 2006a.

. Narrativas espaciais das ações humanas. História e aplicação da arqueologia espacial como teoria de médio alcance: $\mathrm{O}$ caso das estruturas semi-subterrâneas do planalto sul-brasileiro. Revista de Arqueologia, v.19, p.111-23, 2006 b.

Arqueologia da arquitetura: Ensaio sobre complexidade, performance e processos contrutivos das estruturas semi-subterrâneas do planalto gaúcho. In: V ENCONTRO DO NÚCLEO REGIONAL SUL DA SOCIEDADE DE ARQUEOLOGIA BRASILEIRA - SAB/SUL, Rio Grande. Anais... Rio Grande, 2006d.

El uso de la arquitectura como artefacto en el estudio de paisajes arqueológicos del altiplano sur brasileño. Cazadores-recolectores del Cono Sur: Revista de Arqueología, Mar del Plata, v.2, p.15-34, 2007.

As paisagens culturais do planalto sul brasileiro. A aplicação da abordagem da arqueologia da paisagem ao estudo dos sítios arqueológicos do planalto sul brasileiro: estudos de caso no Rio Grande do Sul. In: MACEDO, J.; ANDRADE, R.; TERRA, C. Arqueologia na paisagem. Novos valores, dilemas e instrumentais. Rio de Janeiro: Rio Books, 2012. p.92-122.

COPÉ, S. M. et al. Contribuições para a pré-história do Planalto: estudo da variabilidade de sítios arqueológicos de Pinhal da Serra, RS. Pesquisas, Antropologia, São Leopoldo, n.58, p.121-38, 2002.

COPÉ, S. M.; SALDANHA, J. D. M. Em busca de um sistema de assentamento para o Planalto Sul Rio-Grandense: Escavações no sítio RS-NA-03, Bom Jesus, RS. Pesquisas, Antropologia, São Leopoldo, n.58, p.107-20, 2002. 
CORTELETTI, R. Projeto arqueológico Alto Canoas - Paraca: um estudo da presença Jê no planalto catarinense. 2012. Tese (Doutorado) - Museu de Arqueologia e Etnologia, Universidade de São Paulo. São Paulo, 2012.

DE MASI, M. A. N. Arqueologia das Terras Altas do Sul do Brasil: o baixo vale do rio Canoas, SC. In: (Org.) Xokleng 2860 a.C.: as terras altas do sul do Brasil. Tubarão: Ed. Unisul, 2006. p.47-75.

Centros cerimoniais do planalto meridional: uma análise intrasítio. Revista de Arqueologia, São Paulo, v.22, p.99-113, 2009.

GALLO, S. Conhecimento, transversalidade e currículo. Disponível em: https://www. google.com.br /webhp? sourceid=chrome-instant\&ion $=1$ \&espv=2\&ie $=U T F-8 \# q=$ Gall $\mathrm{o} \% 2 \mathrm{C}+$ conhecimento $\% 2 \mathrm{C}+$ transversalidade $+\mathrm{e}+$ curriculo+2010

HARRIS, D. R.; HILlMAN, G. C. (Ed.) Foraging and farming. The Evolution of Plant Exploitation. In: WORLD ARCHAEOLOGY CONGRESS, 1986: Southampton, England. Unwin Hyman Ltda. Anais... London, 1989.

HERBERTS, A. L.; MÜLLER, L. M. Os sítios funerários do "projeto de arqueologia compensatória UHE Barra Grande - SC". In: XIV CONGRESSO DA SAB, Florianópolis. Anais... Florianópolis, 2007.

IRIARTE, J.; BEHLING, H. The expansion of Araucaria Forest in the southern Brazilian highlands during the last 4000 years and its implications for the development of the Taquara/Itararé Tradition. Environmental Archaeology, v.12, n.2, p.115-27, 2007.

IRIARTE, J. et al. Sacred landscapes of the southern brazilian highlands: Understanging southern proto-Jê moun enclosure complexes. Journal of Anthropological Archaeo-logy, v.32, p.74-96, 2013.

KERN, A. A. (Org.) Arqueologia Pré-histórica do Rio Grande do Sul. Porto Alegre: Mercado Aberto, 1991.

KERN, A. A. et al. Arqueologia de salvamento e a ocupação pré-histórica do vale do rio Pelotas (Municípios de Bom Jesus e Vacaria, RS). Veritas, v.35, n.133, p.99-127, 1989.

MABILDE, P. A. Apontamentos sobre os indigenas selvagens da Nação Coroados dos matos da Província do Rio Grande do Sul: 1836-1866. São Paulo: Ibrasa; Brasília: INL/ Fundação Nacional Pró-Memória, 1983.

MENTZ RIBEIRO, P. A.; RIBEIRO, C. T. Levantamentos arqueológicos no município de Esmeralda, Rio Grande do Sul, Brasil. Revista do CEPA, Santa Cruz do Sul, v.12, n.14, p.49-105, 1985.

MILLER, E. T. Pesquisas arqueológicas efetuadas no Planalto Meridional, Rio Grande do Sul (rios Uruguai, Pelotas e das Antas). In: PROGRAMA NACIONAL DE PESQUISAS ARQUEOLÓGICAS - Resultados preliminares do quarto ano (19681969). Belém: Museu Paraense Emílio Goeldi, Publicações Avulsas, n.15, v. 4, p.3760,1971 .

MOEHLECKE COPÉ, S. Paysages archéologiques du plateau du sud du Brésil. Les grands constructeurs précoloniaux à Bom Jesus, Rio Grande do Sul, Brésil. Berlin: Schaltungsdienst Lange o.H.G.; Éditions Universitaires Européennes, s. d. 401p.

NOELLI, F. S. A ocupação humana na região sul do Brasil: arqueologia, debates e perspectivas - 1972-2000. Revista USP, São Paulo, n.44, p.218-269, 1999/2000. 
PAN - EUROPEAN THEMATIC NETWORK ON CULTURAL LANDSCAPES. Cultural Landscapes in Europe. Fields of Demeter. Haunts of Pan, 2006.

REIS, M. J. A problemática arqueológica das estruturas subterrâneas no planalto catarinense. 1980. Dissertação (Mestrado) - Museu de Arqueologia e Etnologia, Universidade de São Paulo. São Paulo, 1980.

A arqueologia dos buracos de bugre: uma pré-história do planalto meridional. Caxias do Sul: Educs, 2002.

RIBEIRO, P. A. M.; RIBEIRO, C. Levantamentos arqueológicos no município de Esmeralda, RS, Brasil. Revista do CEPA, Santa Cruz, v.12, n.14, p.49-105, 1985.

ROHR, J. A. Os sítios arqueológicos do planalto catarinense, Brasil. Pesquisas: Antropologia, São Leopoldo, v.24, 1971.

SALDANHA, J. D. M. A cerâmica arqueológica de um abrigo funerário relacionado à tradição Taquara: o sítio RS-A-08, Bom Jesus, RS. Cadernos de Resumos do XI Congresso da $S A B$, Rio de Janeiro, 2001.

. Paisagem, lugares e cultura material: uma arqueologia espacial nas Terras Altas do Sul do Brasil. 2005. Dissertação (Mestrado) - Faculdade de História, Pontifícia Universidade Católica. Porto Alegre, 2005.

SALDANHA, J. D. M.; COPÉ, S. M. Análises da ocupação do espaço no interior de uma estrutura semissubterránea. Sítio RS-AN-03, estrutura semissubterrânea C. Bom Jesus, RS. Porto Alegre: SIC-UFRGS, 2001.

SANTOS, M. Uma necessidade epistemológica: a distinção entre paisagem e espaço. In:

A Natureza do espaço. São Paulo: Edusp, 1996, p.103-110. Disponível em: <https://cosmopista.files.wordpress.com/2008/08/santos_a-distincao-entre-paisagem-e-espaco.pdf>.

SCHMITZ, P. I.; BECKER, I. B. Os primitivos engenheiros do Planalto e suas estruturas subterrâneas: a tradição Taquara. In: Pré-história do Rio Grande do Sul. São Leopoldo: IAP, 1991.

SCHMITZ, P. I. O projeto Vacaria: casas subterrâneas no planalto rio-grandense. Pesquisas, São Leopoldo, n.58, p.11-105, 2002a.

. As casas subterrâneas. Fragmentos da história dos índios Kaingang. In: Revista Ciência Hoje, vol.31 n.181, p.23-29, 2002 b.

Pré-história do Rio Grande do Sul. Documentos 05, $2^{\text {a }}$ ed., São Leopoldo, Instituto Anchietano de Pesquisas/Unisinos, 2006.

. Casas subterrâneas no planalto de Santa Catarina: São José dos Cerritos. Pesquisas, São Leopoldo, n.68, p.7-78, 2010.

SILVA, S. B. Etnoarqueologia dos grafismos Kaingang. São Paulo, 2001. Tese (Doutorado em Arqueologia) - Museu de Arqueologia e Etnologia, Universidade de São Paulo.

SOUZA, J. G. Paisagem ritual no planalto meridional brasileiro: complexos de aterros anelares e montículos funerários Jê do Sul em Pinhal da Serra, RS. 2012. Dissertação (Mestrado) - Museu de Arqueologia e Etnologia, Universidade de São Paulo. São Paulo, 2012a. 
SOUZA, J. G. Áreas de atividades em dois centros cerimoniais Jê do Sul: Relações entre arquitetura e função. Revista de Arqueologia, v.25, n.2, p.120-38, 2012 b.

SOUZA, J. G.; COPÉ, S. M. Novas perspectivas sobre a arquitetura ritual do planalto meridional brasileiro: pesquisas recentes em Pinhal da Serra, RS. Revista de Arqueologia, v.23, n.2, p.104-17, 2010.

RESUMO - A aplicação da abordagem da arqueologia da paisagem aos sítios arqueológicos pesquisados nos municípios de Bom Jesus e Pinhal da Serra, no nordeste do Rio Grande do Sul, permitiu identificar cinco momentos marcantes na construção social da paisagem cultural moderna do planalto sul brasileiro. Este artigo enfatiza a importância da temporalidade da paisagem, ressalta as diferenças entre a paisagem dos grandes construtores de estruturas semissubterrâneas e a dos edificadores de estruturas funerárias e assinala que essas não podem ser associadas automaticamente aos grupos denominados Proto-Jê ou aos grupos históricos Jê Meridionais.

PALAVRAS-CHAVES: Paisagens culturais, Planalto sul brasileiro, Arqueologia da paisagem, Patrimônio paisagístico.

ABSTRACT - The use of landscape archeology approach to archaeological sites surveyed in the municipalities of Bom Jesus and Pinhal da Serra, in the northeast of Rio Grande do Sul, identified five key moments in the social construction of modern cultural landscape of the southern Brazilian plateau. This article emphasizes the importance of the temporality of the landscape and highlights the differences between the landscape of the great builders of pit houses and the builders of the monumental funerary structures and points out that these cannot be automatically associated with the so-called Proto-Jê groups or the historical Southern Jê groups.

KEYWORDS: Cultural landscapes, Brazilian southern plateau, Archaeology of the landscape, Heritage landscape.

Silvia Moehlecke Copé é professora associada do Departamento de História da Universidade Federal do Rio Grande do Sul. Núcleo de Pesquisa Arqueológica - NuPArq. @ - copemsilvia@gmail.com

Recebido em 23.2.2015 e aceito em 13.3.2015.

${ }^{\text {I }}$ Departamento de História, Universidade Federal do Rio Grande do Sul, Porto Alegre/ RS, Brasil. 
